\title{
Characteristic evaluation of 20-bit consecutive codes in high performance optical burst mode receiver configuration
}

\author{
Adibah Mazwar ${ }^{1}$, Azura Hamzah ${ }^{2}$, Sevia Mahdaliza Idrus ${ }^{3}$, Atsushi Kanno ${ }^{4}$, Norliza Mohamed ${ }^{5}$ \\ ${ }^{1,2}$ Department of Electronic Systems Engineering, Malaysia-Japan International Institute of Technology, \\ Universiti Teknologi Malaysia, Malaysia \\ ${ }^{3}$ School of Electrical Engineering, Faculty of Engineering, UTM, Malaysia \\ ${ }^{4}$ National Institute of Information and Communications Technology, Japan \\ ${ }^{5}$ RAZAK Faculty of Technology and Informatics, Universiti Teknologi Malaysia, Malaysia
}

\section{Article Info \\ Article history: \\ Received Oct 1, 2018 \\ Revised Dec 10, 2018 \\ Accepted Jan 25, 2019 \\ Keywords: \\ Bessel filter \\ Burst mode receiver \\ Consecutive codes \\ Step response \\ Transfer function}

\begin{abstract}
Optical burst mode receivers are indispensable components for Passive Optical Network (PON) and Ethernet Optical Access Network (E-OSAN). An optical burst mode receiver with transfer function $G_{n}\left(j \omega / \omega_{0}\right)=1$ $H_{n}\left(j \omega / \omega_{0}\right)$ is proposed, of which better performance is anticipated than that of conventional AC-coupling. Next, an optical burst mode receiver with fast response $G_{n}\left(j \omega / \omega_{F}\right)$ and slow response $G_{n}\left(j \omega / \omega_{s}\right)$, whereby $G_{n}\left(j \omega_{1} / \omega_{F}\right)$ switches to $G_{n}(j \omega / \omega s)$ right after the DC component of the input burst signal converges to 0 is proposed. Then, an automatically switching circuit that switches fast response $G_{n}\left(j \omega / \omega_{F}\right)$ to slow response $G_{n}\left(j \omega / \omega_{s}\right)$ circuits right after the maximum peak value of the output burst $G_{n}\left(j \omega / \omega_{F}\right)$ is $1 / 2$ and the DC components of the input burst converges to 0 is also proposed. This paper presents the experiments on same consecutive codes in burst mode receivers using the proposed automatically switching circuit, with evaluation on its characteristics made through simulation.
\end{abstract}

Copyright (c) 2019 Institute of Advanced Engineering and Science. All rights reserved.

Corresponding Author:

Azura Hamzah,

Department of Electronic Systems Engineering,

Malaysia-Japan International Institute of Technology,

Universiti Teknologi Malaysia,

Jalan Sultan Yahya Petra, 54100 Kuala Lumpur, Malaysia.

Email: azurahamzah@utm.my

\section{INTRODUCTION}

Optical burst mode receivers are essential for Optical Line Terminals (OLTs) in Time Division Multiplexing based Passive Optical Networks (TDM-PONs) [1-5]. Optical burst mode receivers [6-8] are also crucial components for both Optical Network Units (ONUs) and OLTs in Ethernet Optical Switched Access Networks (E-OSANs) [9].

Previously, Nomura et al. developed a prototype E-OSAN system. They contrived optical burst mode receivers with $\mathrm{AC}$-coupling using commercial components [10-12]. In improving the performance of the AC-coupling receivers, Ueda et al. engineered an optical burst mode receiver with transfer function $G_{n}\left(j \omega / \omega_{0}\right)=1-H_{n}\left(j \omega / \omega_{0}\right)$, where $H_{n}\left(j \omega / \omega_{0}\right)$ denotes the transfer function of a Bessel filter with degree $n$. This proposal generalizes the AC-coupling to $n=1$ [13-15]. Afterwards, they proposed a design method transfer function $G_{n}\left(j \omega / \omega_{0}\right)$ and evaluated the optical burst mode receiver that employ the designed transfer function $G_{n}\left(j \omega / \omega_{0}\right)$. They also introduced a method for realizing LCR circuits from the designed transfer function $G_{n}\left(j \omega / \omega_{0}\right)$ [16-19].

Based on [5, 6], a stable optical burst mode receiver with shorter clock recovery time is proposed. The proposed configuration uses a fast response transfer function $G_{n}\left(j \omega / \omega_{F}\right)$ to eliminate DC components rapidly from the input burst, which is then replaced by a slow response transfer function $G_{n}\left(j \omega^{\prime} / \omega_{S}\right)$ 
immediately after the DC component of the input burst signal converges to 0 . This proposed configuration manually switches the fast response transfer function $G_{n}\left(j \omega / \omega_{F}\right)$ to a slow response transfer function $G_{n}\left(j \omega / \omega_{S}\right)$ at selected switching time [20].

Based on [21], a method for automatically switching between fast response circuit $G_{n}\left(j \omega / \omega_{F}\right)$ and slow response circuit $G_{n}\left(j \omega / \omega_{S}\right)$ is proposed. The proposed method automatically switches the fast response circuit $G_{n}\left(j \omega / \omega_{F}\right)$ to a slow response circuit $G_{n}\left(j \omega / \omega_{S}\right)$ right after the maximum peak value of the output burst of $G_{n}\left(j \omega / \omega_{F}\right)$ is $1 / 2$, and the DC components of the input burst converges to 0 . The slow response circuit $G_{n}\left(j \omega / \omega_{S}\right)$ then automatically re-switches to a fast response circuit $G_{n}\left(j \omega / \omega_{F}\right)$ when the burst signal ends [22]. The performance of the proposed configuration in [23] with 10-bit consecutive code placed at selected times is then evaluated and showed that the fast response circuit $G_{n}\left(j \omega / \omega_{F}\right)$ automatically switches to slow response circuit $G_{n}\left(j \omega / \omega_{S}\right)$ right after the maximum peak value of output burst of $G_{n}\left(j \omega / \omega_{F}\right)$ is $1 / 2$, i.e. uninfluenced by the 10-bit consecutive codes [24-25]. This paper presents the performance evaluation of a 20-bit consecutive code in the automatically switching fast response $G_{n}\left(j \omega / \omega_{F}\right)$ and slow response $G_{n}\left(j \omega / \omega_{S}\right)$ circuits.

\section{RESEARCH METHOD}

This paper presents the performance evaluation on 20-bit consecutive 0 and 1 code in burst mode receiver. Using an automatic switch between fast response $G_{n}\left(j \omega / \omega_{F}\right)$ and slow response $G_{n}\left(j \omega / \omega_{S}\right)$ circuits, 20 bits of the same consecutive 0 and 1 code will be placed at the vicinity of switching mechanism at time, $t_{u}$ $=2,4,6,8,10 \mathrm{~ns}$ of the input burst signals.

Previously, 10 bits of the same consecutive 0 and 1 code is placed at the vicinity of switching mechanism occurring at time, $t_{u}=2,4,6,8,10 \mathrm{~ns}$ of the input burst signal using the same automatic switching between the two circuits.

The automatic switching LCR circuit switches the fast response circuit $G_{n}\left(j \omega / \omega_{F}\right)$ to slow response circuit $G_{n}\left(j \omega / \omega_{S}\right)$ right after the maximum peak value of the output burst of $G_{n}\left(j \omega / \omega_{F}\right)$ reaches $1 / 2$, and the DC components of input burst converges to 0 . The slow response circuit $G_{n}\left(j \omega / \omega_{S}\right)$ then automatically reswitches to the fast response circuit $G_{n}\left(j \omega / \omega_{F}\right)$ when the burst signal ends [7].

Function block of the automatic switch between fast response $G_{n}\left(j \omega / \omega_{F}\right)$ and slow response $G_{n}\left(j \omega / \omega_{S}\right)$ circuits are shown in Figure 1 while Figure 2 (a) (h) shows the signal waveforms for each (a) (h) in Figure 1.

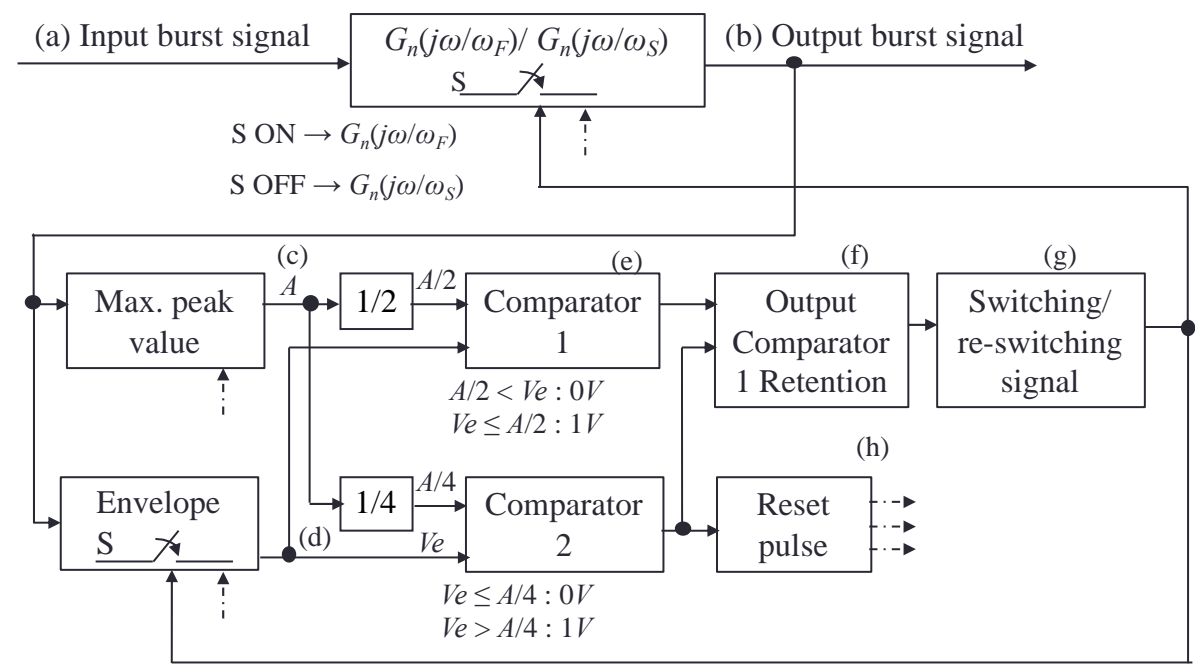

Figure 1. Function block of automatically switching LCR circuit

The maximum peak output value A is shown in Figure 2(c). The output from comparators 1 and 2 are received and held at comparator 1 retention part, as shown in Figure 2(f). According to Figure 2(d), if the output of the envelope value $V_{e}$ is $V_{e}>A / 2, V_{e}>A / 4$, the output from comparator 1 retention part becomes $0 \mathrm{~V}$; if $A / 4<V_{e}<A / 2$, the output becomes $1 \mathrm{~V}$. Then, the switching/re-switching signal is generated by inverting the signal waveform at Figure 2(d), as shown in Figure 2(g). If the output is 1V, switch $\mathrm{S}$ will be 
turned ON, and $G_{n}\left(j \omega / \omega_{F}\right)$ circuit is selected. If the output is $0 \mathrm{~V}$, switch S will be turned OFF, and $G_{n}\left(j \omega / \omega_{S}\right)$ circuit is selected.

For the output of comparator 2 , if $V_{e}>A / 4$, the output becomes $1 \mathrm{~V}$; if $V_{e}<A / 4$, the output becomes $0 \mathrm{~V}$. As a result, the amplitude of the envelope drops until $A / 4$, thus indicating the end of a burst signal. When the end of a burst signal is detected, the output of switching/re-switching signal becomes $1 \mathrm{~V}$, and $G_{n}\left(j \omega / \omega_{S}\right)$ is re-switched to $G_{n}\left(j \omega / \omega_{F}\right)$ circuit, as shown in Figure 2(d).

Reset pulse signal shown in Figure 2(g) is generated by differentiating the signal in Figure 2(d), and each part of the electric charge realized from the capacitor is released. Besides that, the loop of the coil is open, and the accumulative energy is released instantaneously after the re-switching mechanism is activated.

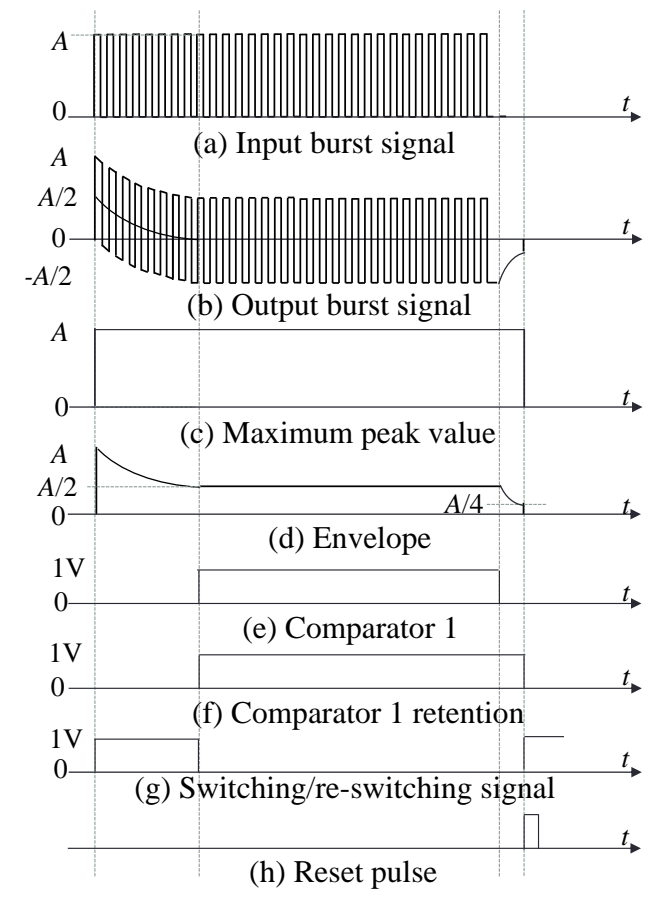

Figure 2. Signal waveform of automatically switching LCR circuit

\section{RESULTS AND ANALYSIS}

The automatic switching between fast response $G_{n}\left(j \omega / \omega_{F}\right)$ and slow response $G_{n}\left(j \omega / \omega_{S}\right)$ circuits is designed from a simulation in PSpice, and the characteristics of 10-bit and 20-bit 0, 1 consecutive codes are evaluated. The design of the automatically switching circuit is shown in Figure 3.

\subsection{0-Bit Consecutive Codes}

A similar 10-bit consecutive 0 code is placed at the vicinity of switching mechanism occurring at time, $t_{u}=2,4,6,7,8 \mathrm{~ns}$ of the input burst signal. Then, the characteristics of the output burst signal are evaluated. As shown in Figure 4, the result shows that fast response circuit $G_{n}\left(j \omega / \omega_{F}\right)$ automatically switches to slow response circuit $G_{n}\left(j \omega / \omega_{S}\right)$ right after the maximum peak value of the output burst of $G_{n}\left(j \omega / \omega_{F}\right)$ is $1 / 2$, and the DC components of the input burst converges to 0 , regardless of the consecutive codes.

Subsequently, similar 10-bit consecutive codes of 1 are placed at the vicinity of switching mechanism at time $t_{u}=2,4,6,7,8 \mathrm{~ns}$ of the input burst signal, and the characteristics of the output burst signal are evaluated. Figure 5 shows the anticipated result, similarly unaffected by the presence of the consecutive codes.

\subsection{0-Bit Consecutive Codes}

Similarly, 20 bits of similar consecutive codes of 0,1 are situated at the vicinity of the switching mechanism occurring at time $t_{u}=2,4,6,7,8 \mathrm{~ns}$ of the input burst signal, and the characteristics of output burst signal are evaluated. Based on Figure 6 and Figure 7, when 20 bits of the same consecutive codes of 0 , 1 are placed at the vicinity of switching mechanism occurring at time $t_{u}=4 \mathrm{~ns}$ and $t_{u}=2$, the results are unobtainable due to the output burst signal being affected by the existence of the consecutive codes. 


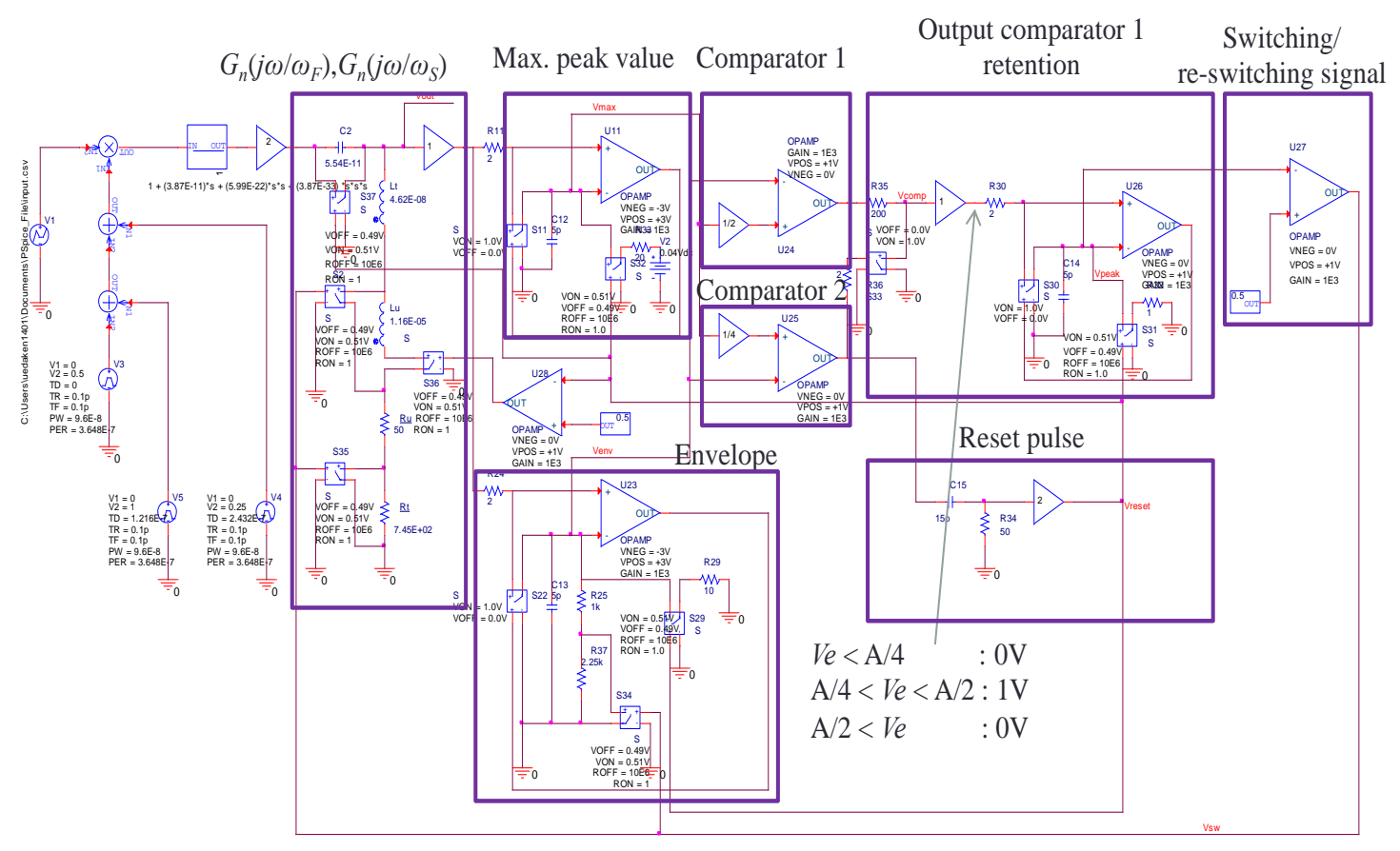

Figure 3. Example of automatically switching circuit in PSpice

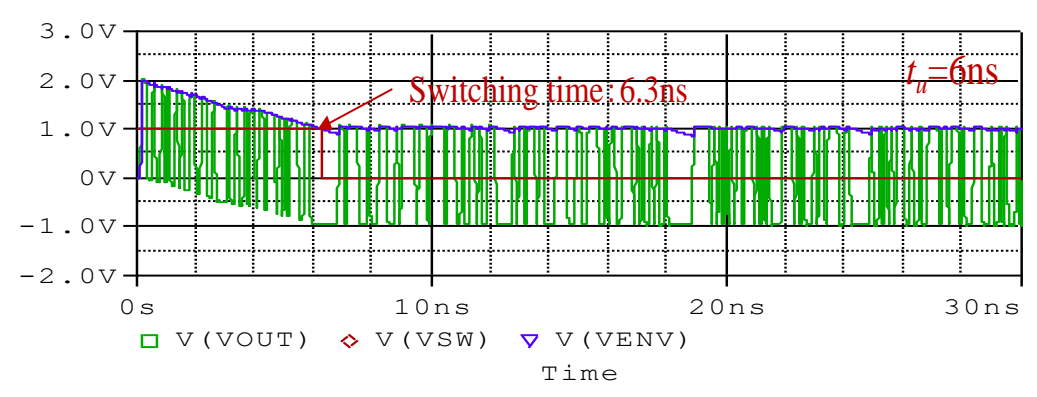

Figure 4. 10 bits of 0 code

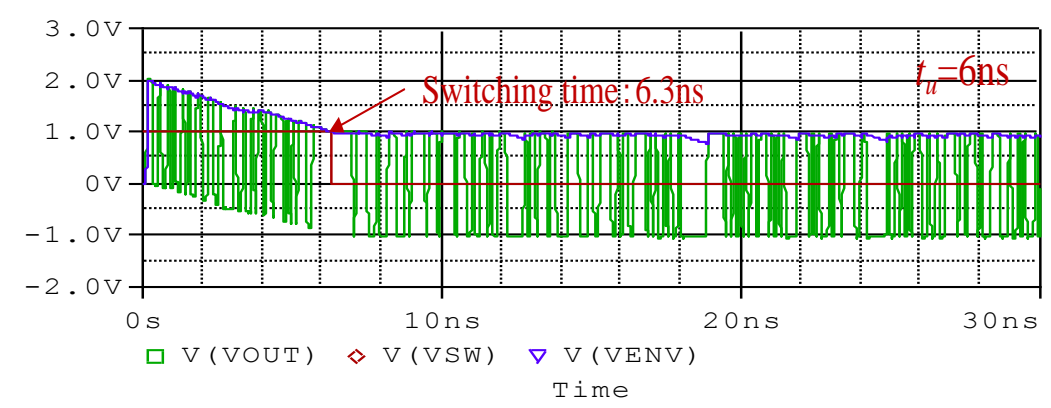

Figure 5.10 bits of 1 code

\subsection{Discussion}

Based on the characteristics analyses in Figure 6 , the fast response $G_{n}\left(j \omega / \omega_{F}\right)$ switches to slow response $G_{n}\left(j \omega / \omega_{S}\right)$ circuits at switching time $t=5.6 \mathrm{~ns}$. For switching time $t>5.6 \mathrm{~ns}$, the envelope value $V_{e}$ is $V_{e}>1$, as shown in Figure 8(b). When $t=5.6 \mathrm{~ns}$ is detected, the output of comparator 1 should become Vcomp $=$ High (1V). However, Vcomp remains as Vcomp = Low (0V), as shown in Figure 8(c). This causes 
the output of comparator 1 retention, Vpeak to gradually decrease from $1 \mathrm{~V}$ to $0.5 \mathrm{~V}$ as shown in Figure 8 (d), and switch $V s w$ switches from OFF to ON. Correspondingly, the slow response $G_{n}\left(j \omega / \omega_{S}\right)$ re-switches to fast response $G_{n}\left(j \omega / \omega_{F}\right)$ circuit at $t=19.0 \mathrm{~ns}$.

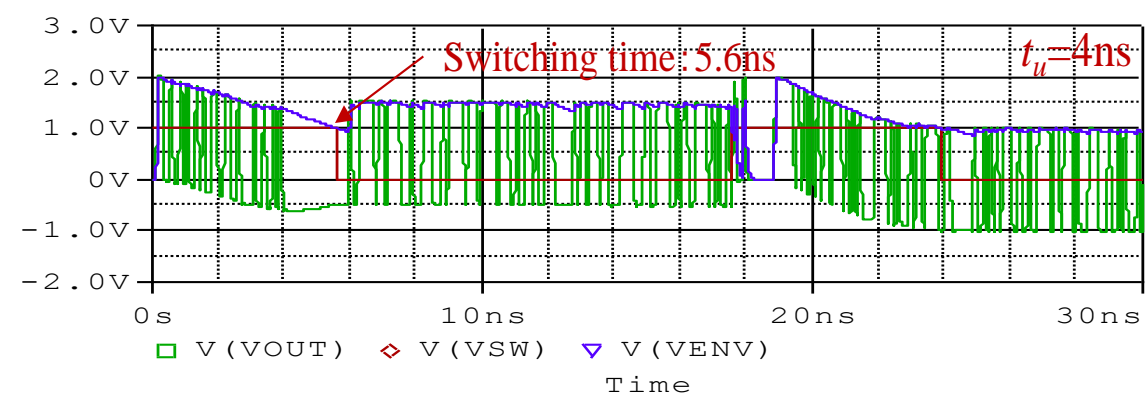

Figure 6. 20 bits of 0 code

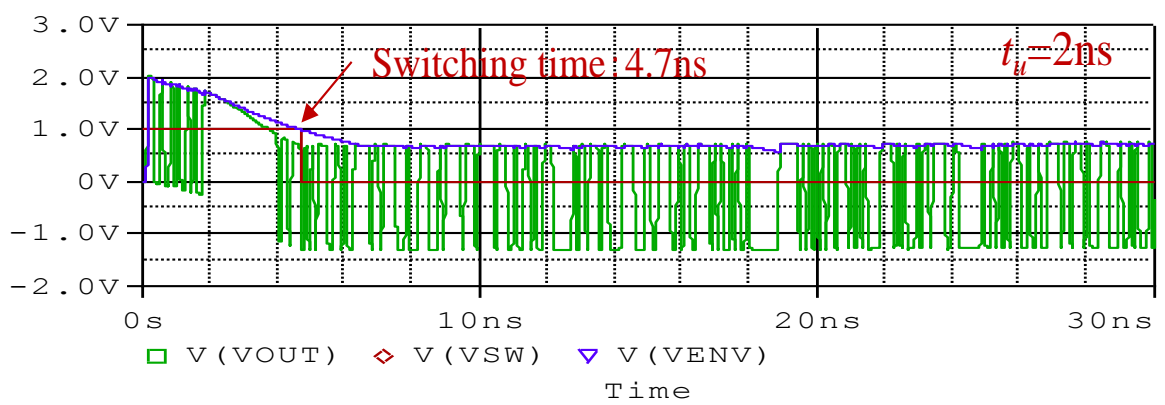

Figure 7. 20 bits of 1 code

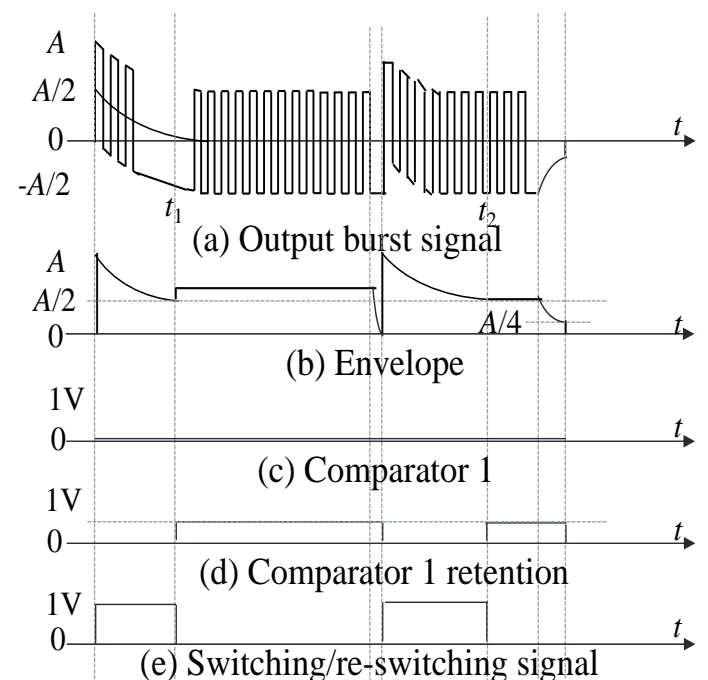

Figure 8. Signal waveform of evaluation in Figure 6 


\section{CONCLUSION}

The evaluation on similar 10-bit consecutive codes in the burst mode receiver shows better performance than that of the 20-bit consecutive codes. This confirms an instantaneous automatic switching from fast response circuit $G_{n}\left(j \omega / \omega_{F}\right)$ to slow response circuit $G_{n}\left(j \omega / \omega_{S}\right)$ after the maximum peak value of output burst of $G_{n}\left(j \omega / \omega_{F}\right)$ is $1 / 2$, and the DC components of input burst converges to 0 , uninfluenced by the existence of the consecutive codes. Items for further study may involve the enhancement and assessment of the 20-bit consecutive codes in burst mode receiver through simulations.

\section{ACKNOWLEDGEMENTS}

This work was supported in part by Universiti Teknologi Malaysia under Grant Nos Q.K130000.2543.17H26.

\section{REFERENCES}

[1] IEEE Std 802.3-2012, "IEEE Standard for Ethernet, Section Five," IEEE Computer Society, 2012.

[2] H. Ueda, et al., "New optical access network architecture using optical packet switches," IEICE Trans. Commun., vol. E89-B, pp. 724-730, 2006.

[3] T. Nomura, et al., "Development of gigabit Ethernet optical switched access network system using optical packet switches," IEICE Trans. Commun., vol. E91-B, pp. 2485-2493, 2008.

[4] H. Ueda, et al., "Proposal of novel optical burst signal receiver for ONU in optical switched access network," IEICE Trans. Commun., vol/issue: E95-B(3), pp. 819-831, 2012.

[5] A. B. Mazwar, et al., "10Gbps optical burst mode receiver with high performance," IEICE Trans. Commun., vol/issue: 115(439), pp. 45-52, 2015.

[6] A. B. Mazwar, et al., "High Performance 10Gbps optical burst mode receiver with fast response and high stability," IEEE ICC 2016, 2016.

[7] A. B. Mazwar, et al., "High Performance 10 Gbps Optical Burst Mode Receiver Configuration: A Method for Automatically Switching between Two Transfer Functions," IEICE Trans. Commun., vol/issue: 116(468), pp. 3542, 2017.

[8] T. Yanagisawa and Y. Kambayashi, "Theory and Design of Filters," Electronics Sciences series 55, Sampo-sha, 1980. (in Japanese, and the book title is translated into English by the authors)

[9] H. Nishizawa and Y. Yamada, "Design of a 10-Gb/s burst-mode optical packet receiver and its demonstration in a WDM optical switching network," J. Lightw. Technol., vol/issue: 20(7), pp. 1078-1083, 2002.

[10] Y. Ota and R. G. Swartz, "Burst mode compatible optical receiver with large dynamic range," J. Lightw. Technol., vol/issue: 8(12), pp. 1897-1903, 1990.

[11] C. Su, et al., "DC-1 Gb/s burst-mode compatible receiver for optical bus application," J. Lightw. Technol., vol/issue: 10(2), pp. 244-249, 1992.

[12] L. M. Lunardi, et al., "High-speed burst-mode OEIC photo receiver using InP/InGaAs hetero junction bipolar transistors," Proc. OFC, San Jose, CA, pp. 30-31, 1994.

[13] C. A. Eldering, "Theoretical determination of sensitivity penalty of burst mode: Fiber optic receiver," J. Lightw. Technol., vol/issue: 11(12), pp. 2145-2149, 1993.

[14] C. Su, et al., "BER performance of digital optical burst-mode receiver in TDMA all optical Multi access networks," IEEE Photon. Technol. Lett., vol/issue: 7(1), pp. 132-134, 1995.

[15] P. M. Valdes, "Performance of optical direct receivers using noise corrupted decision threshold," J. Lightw. Technol., vol/issue: 13(11), pp. 2202-2214, 1995.

[16] T. Bakker, "Decision threshold based on dynamic offset compensation for burst-mode receiver," Proc. 27th Eur Conf. Opt. Comm., pp. 222-223, 2001.

[17] R. G. Swart, "A burst-mode, packet capable and automatic dark level compensation for optical bus communication," VLSI Symp. Tech Dig., pp. 67-68, 1993.

[18] M. S. Leeson, "Calculation of sensitivity penalty for optically pre amplified burst mode receivers using FabryPerot Filters," Electron. Lett, vol/issue: 34(11), pp. 1121-1122, 1998.

[19] Seo, "A $1.25 \mathrm{~Gb} / \mathrm{s}$ high sensitive peak detector in optical burst-mode receiver using a $0.18 \mathrm{~m}$ CMOS technology," Proc. ICCT, pp. 644-646, 2003.

[20] S. Brigati, "A SiGe BiCMOS burst-mode 155-Mb/s receiver for PON," IEEE J. Solid-State Circuits, vol/issue: 37(7), pp. 887-897, 2002.

[21] B. C. Thomsen, "Optically equalized $10 \mathrm{~Gb} / \mathrm{s}$ digital burst mode receiver for dynamic optical networks," Opt. Express, vol/issue: 15(15), pp. 9520-9526, 2007.

[22] Optical Zonu Corp. [Online]. Available: www.opticalzonu.com

[23] C. Su, "Inherent transmission capacity penalty of burst-mode receiver for optical multiaccess networks," IEEE Photon. Technol. Lett., vol/issue: 6(5), pp. 664-667, 1994.

[24] C. Su, et al., "Theory of burst mode optical receiver and its application in optical multi-access networks," $J$. Lightw. Technol., vol/issue: 15(4), pp. 590-606, 1997.

[25] C. Lee, et al., "BA systematic evaluation on burst-mode data transmission in passive optical access network," Proc. ICCT, Beijing, China, pp. 578-581, 1996. 


\section{BIOGRAPHIES OF AUTHORS}
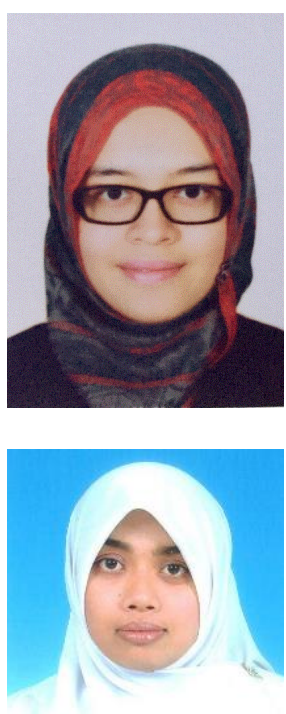

Azura Hamzah is a Senior Lecturer at Malaysia-Japan International Institute of Technology (MJIIT), Universiti Teknologi Malaysia. In MJIIT, she is a Full Member for Optical Devices and Systems Ikohza (ODESY) and an Associate Member for Disaster Preparedness and Prevention Centre (DPPC). She received her Bachelor's degree in Communication Engineering from International Islamic University Malaysia, Malaysia in 2005 and the Master's and PhD degree from Universiti Malaya, Malaysia in 2009 and 2012. Her research interests are in optical amplifier and laser, pulse laser, optical sensor, optical interconnect and rare-earth-doped optical devices. She is a senior member for The Institution of Electrical and Electronics Engineers.

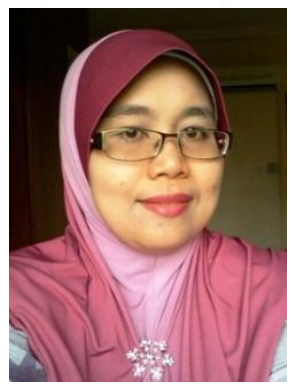

Sevia Mahdaliza Idrus is Professor and faculty member of the School of Electrical Engineering UTM. She received her Bachelor in Electrical Engineering in 1998 and Master in Engineering Management in 1999, both from UTM. She obtained her Ph.D in 2004 from University of Warwick, United Kingdom in communication engineering. She has served UTM since 1998 as an academic and administrative staff. Her main research interests are optical communication system and network, IoT solution, and engineering management. Her research output have been translated into a number of publications and IPR including a high-end reference books, 'Optical Wireless Communication: IR Connectivity' published by Taylor and Francis, 5 books published by Pearson, Springer and Novar respectively, 49 books chapters and monographs, over 150 technical papers, 5 patents granted, 35 patent filings and holds 32 UTM copyrights. She is the founder and Director of UTM spin-off company, iSmartUrus Pte Ltd and a start-up Zen Trilions Pte Ltd which focus on commercialization University's product. She actively involved in international collaboration project and appointed as Guest Professor at Osaka Prefecture University and Tokai University in Japan 2011 and 2014 respectively.

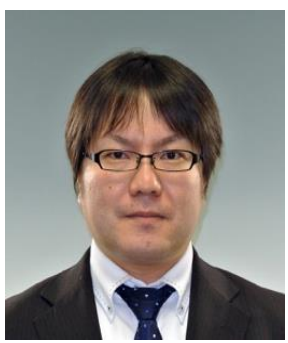

Atsushi Kanno received B.Sci., M.Sci., and Ph.D. degree in science from the University of Tsukuba, Japan, in 1999, 2001, and 2005, respectively. In 2005, he was with the Venture Business Laboratory of the Institute of Science and Engineering, University of Tsukuba. In 2006, he joined the National Institute of Information and Communications Technology (NICT), Japan. His research interests are microwave/millimeter-wave/terahertz photonics, ultrafast optical and radio communication systems, lithium niobate optical modulators, and ultrafast phenomena in semiconductor optical devices. He is a member of the Institute of Electronics, Information and Communication Engineers (IEICE), the Japan Society of Applied Physics (JSAP), the Laser Society of Japan, and the Institute of Electrical and Electronic Engineers (IEEE).

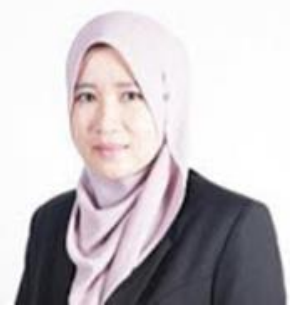

Norliza Mohamed received her B. Eng. (Hons) and Master degree in Electrical Engineering from Universiti Teknologi Malaysia (UTM) in 2001 and 2003 respectively. Later she continues her study also in UTM and received her PhD degree in 2013. She currently works as a senior lecturer for Razak Faculty of Technology and Informatics, UTM Kuala Lumpur. Her expertise is in optical communication particularly in radio over fiber system. Her research interest includes optoelectronics devices, RF mixer design, frequency conversion and wireless communication for $5 \mathrm{G}$ technologies. 